\title{
Traumatic Brain Injury and Aging: Is a Combination of Progesterone and Vitamin D Hormone a Simple Solution to a Complex Problem?
}

\author{
Milos Cekic and Donald G. Stein \\ Emory University School of Medicine, Department of Emergency Medicine, Atlanta, Georgia 30322
}

\begin{abstract}
Summary: Although progress is being made in the development of new clinical treatments for traumatic brain injury (TBI), little is known about whether such treatments are effective in older patients, in whom frailty, prior medical conditions, altered metabolism, and changing sensitivity to medications all can affect outcomes following a brain injury. In this review we consider TBI to be a complex, highly variable, and systemic disorder that may require a new pharmacotherapeutic approach, one using combinations or cocktails of drugs to treat the many components of the injury cascade. We review some recent
\end{abstract}

research on the role of vitamin D hormone and vitamin D deficiency in older subjects, and on the interactions of these factors with progesterone, the only treatment for TBI that has shown clinical effectiveness. Progesterone is now in phase III multicenter trial testing in the United States. We also discuss some of the potential mechanisms and pathways through which the combination of hormones may work, singly and in synergy, to enhance survival and recovery after TBI. Key Words: Traumatic brain injury, aging, frailty, progesterone, vitamin D, morphological and functional recovery, systems.

\section{INTRODUCTION}

Human traumatic brain injury (TBI) is a notoriously complex and heterogeneous disease process. ${ }^{1,2}$ From the initial insult to the highly destructive secondary damage cascade to eventual reorganization and recovery, ${ }^{3,4}$ each phase of the injury cascade involves a different set of processes, which sometimes overlap and sometimes do not. At least in part because of this complexity, most drugs designed as monotherapies to modulate single receptors or related groups of mechanisms have failed in clinical trials for TBI, despite showing preclinical promise. ${ }^{5,6}$ In addition to the complexity inherent in the injury process itself, the systemic and extraneuronal effects of trauma need to be considered, because these are often the actual causes of death in brain-injured patients. ${ }^{7}$

A variety of additional factors such as age and ageassociated systemic alterations can also affect both survival and recovery from severe injury. These include changes in hormonal and drug metabolism, nutritional status, immune function, and increased frailty, among

Address correspondence and reprint requests to: Donald G. Stein, Ph.D., Emory University, 1365 B Clifton Road NE, Suite 5100, Atlanta GA 30322. E-mail: dstei04@emory.edu. other factors. Given this added layer of complexity, it is not obvious that the injury itself or putative treatments for it will behave in the same way in older subjects as they do in young adults. This population might therefore require not only special research consideration, but also a different treatment paradigm, which could potentially involve combination treatments designed specifically to address an age-altered physiology.

\section{TBI IS A MULTIORGAN SYSTEMIC INFLAMMATORY DISORDER}

Acute phase events with the greatest import for survival after TBI appear to be those related to inflammatory processes, especially the production of inflammatory cytokines, which is a well-recognized aspect of the physiological response to trauma. ${ }^{8}$ Levels of inflammatory cytokines are the most consistent prognostic markers of outcomes in patients with systemic inflammatory response syndrome, sepsis, multiorgan dysfunction syndrome, and multiorgan failure, ${ }^{9}$ all of which are commonly the proximate cause of death after CNS trauma ${ }^{7,10,11}$ and generally result from an imbalance between pro- and anti-inflammatory responses to severe injury. ${ }^{10}$ We therefore support the view that TBI should be considered a systemic and not just a focal prob- 
lem, especially in the context of inflammation and shortterm survival.

Systemic effects are also evident in response to oxidative stress. Shohami et al. ${ }^{12}$ reported that TBI induces a cascade of highly reactive oxygen species that can damage brain tissue and other organs throughout the body. Using sophisticated methods to measure the ability of tissue to scavenge free radicals as a measure of oxidative stress, the investigators found that closed head injury in male rats led to widespread changes in brain, liver, lung, skin, kidney, and intestine within $24 \mathrm{~h}$ of the insult. More recently Moinard et al. ${ }^{13}$ found significantly altered metabolism and mitochondrial activity in the liver triggered by the TBI-induced inflammatory cascade in the brain. Histological examination of liver tissue showed that the TBI caused immune cell infiltration, edema, fibrosis, and necrosis that helped to block normal liver metabolism and homeostasis.

Inflammatory markers are not just causally related to mortality after TBI, but also appear to be a good index of the extent of injury ${ }^{9,14}$ and reliable independent predictors of injury outcome. ${ }^{15-18}$ Although the levels of the cytokines tumor necrosis factor- $\alpha(\mathrm{TNF} \alpha)$ and interleukin-1 $\beta$ (IL-1 $\beta$ ) increase after severe injury, it is the level of IL- 6 that is considered the most accurate prognostically, because it is the chief regulator of acute hepatic response $^{19}$ and correlates with systemic inflammation and outcome. ${ }^{9}$ There is also evidence that early increased levels of IL-6 can be a marker of high risk of complication and organ failure..$^{20}$ Although it has been argued that systemic inflammation is so complex that it defies traditional reductionist definitions and may not be useful in predicting system behaviors, ${ }^{21}$ modulating the production of inflammatory cytokines during the acute phase could be of benefit in reducing mortality and improving the prognosis for better functional outcomes. For example, there is recent evidence of sex differences in patients with multiple trauma, with premenopausal women showing significantly lower plasma cytokines and less multiorgan failure and sepsis, compared with age-matched men. ${ }^{22}$ It is possible that these sex differences in response to injury are attributable to higher circulating levels of progesterone $\left(\mathrm{P}_{4}\right)$ in female subjects, ${ }^{23,24}$ an intriguing hypothesis, given the success of $\mathrm{P}_{4}$ in treating TBI.

\section{PROGESTERONE AND BRAIN INJURY TREATMENT}

A number of recent publications have demonstrated effectiveness of $\mathrm{P}_{4}$ treatment in experimental models of TBI. ${ }^{25-29}$ It has been consistently shown that post-injury administration of $\mathrm{P}_{4}$ can attenuate the cytological, morphological, and functional deficits caused by traumatic injury. ${ }^{27,30-35}$ Unlike other sex steroids, $\mathrm{P}_{4}$ is synthe- sized by oligodendrocytes in the brain, where it then acts on membrane-bound and classical nuclear steroid receptors. ${ }^{36}$ Progesterone can also affect water channel proteins (aquaporins) to modulate both vasogenic and cytotoxic edema, ${ }^{37,38}$ reduce glutamate toxicity, mediate toxic calcium influx by its antagonist effects on sigma receptors, upregulate $\mathrm{GABA}_{\mathrm{A}}$ receptors to reduce excitotoxic damage, and reduce apoptosis and necrosis. ${ }^{29,36}$ It is likely that the pleiotropic and systemic nature of $\mathrm{P}_{4}$ is responsible for its effectiveness in the treatment of TBI. As one recent review suggests, "given the multifactorial nature of the secondary injury process, it is unlikely that targeting a single factor will result in significant improvement in outcome. Conversely, targeting several injury factors may be the most likely therapeutic approach to improve outcome" (p. 29, emphasis added). Progesterone is just such a multifactorial agent.

The preclinical findings on neuroprotective effects of $\mathrm{P}_{4}$ have been confirmed in humans in a recently completed phase IIa single-center clinical trial for $\mathrm{P}_{4}$ in the treatment of moderate to severe adult TBI $(N=100) .{ }^{39}$ Mortality among patients given $\mathrm{P}_{4}$ intravenously for 3 days after the injury was less than half that of controls provided standardof-practice care but no hormone (13.6\% vs 30.4\%). Functional outcomes at 30 days were significantly better for moderately injured patients given $\mathrm{P}_{4}$ than for the placebo group, and a data safety monitoring board appointed by the U.S. National Institutes of Health found no serious adverse events attributable to $\mathrm{P}_{4}$ treatment. This was the first successful clinical trial for the treatment of TBI in more than 30 years of research.

A second independent, randomized double-blind study from China examined $\mathrm{P}_{4}$ in 159 patients with severe TBI given an intramuscular course of $\mathrm{P}_{4}$ treatment over 5 days. Similar beneficial outcomes on morbidity and mortality were observed at both 30 days and 6 months after injury, again without any serious adverse events caused by the treatment. ${ }^{40}$

A phase III, 17-center, double-blind, randomized clinical trial for TBI will start enrolling about 1000 patients in January 2010 (NCT00822900; http://www.clinicaltrials. gov).

One specific reason for increased survival in $\mathrm{P}_{4}$-treated TBI patients may be the ability of $\mathrm{P}_{4}$ to substantially reduce systemic acute-phase inflammation and so prevent multiorgan dysfunction syndrome and multiorgan failure. In support of this idea, Chen et al..$^{41}$ found that contusion injury to the cerebral cortex in rats induced expression of IL- $1 \beta$ and TNF $\alpha$ in the intestinal mucosa, followed by apoptosis in the intestinal mucosa. A 5-day course of treatment with $\mathrm{P}_{4}$ reduced both the cytokines and cell death in the intestine, demonstrating the systemic benefits of $\mathrm{P}_{4}$ administration. 


\section{AGING AND BRAIN INJURY}

Although the incidence of TBI has decreased in most age groups because of improved primary prevention (such as seat belt and safety helmet use), it has increased by $21 \%$ in people over the age of $65 .{ }^{42}$ Age is itself an independent predictor of mortality due to TBI, which in the geriatric population is twice that of younger age groups. ${ }^{43}$ The age distribution of hospitalizations due to TBI has the most pronounced peak late in the eighth decade, ${ }^{44}$ and the highest mortality rates from TBI, ranging from $60.9 \%$ to $86.8 \%$ depending on the study, occur in people 75 to 80 years old. ${ }^{45}$ Given the magnitude of the problem, it is important to address the effectiveness of any treatment specifically in aged subjects.

Old animals are fatter, more sedentary and irritable, and (like most old people) have sensory, cognitive, and motor deficits that can exacerbate injury-induced impairments and impede functional recovery. Old rats and old people also metabolize drugs differently than young ones, so doses and agents that work in younger subjects might not work in older animals, or could even aggravate the injury. A number of systemic physiological changes associated with the aging process could also alter drug effectiveness, such as altered metabolism and endogenous hormonal milieu, ${ }^{46-50}$ impaired immune function, ${ }^{51-53}$ increased levels of systemic inflammation, ${ }^{54}$ and reduced physiological reserve or frailty. ${ }^{55,56}$ Additional changes within the CNS, including reduced plasticity ${ }^{57}$ and more subtle chemical, structural, morphological, and network alterations, ${ }^{58,59}$ can also significantly affect the ability of an older animal or person to survive and recover from severe injury.

\section{CNS effects of aging}

Although it is established that there is no overt loss of neurons in the brain with normal aging, a number of more subtle structural, chemical, and metabolic changes occur, ${ }^{58,59}$ both at the level of individual neurons and in medium-scale neuronal networks, that can significantly affect the ability of the CNS to adapt to internal and environmental changes. Other changes in the CNS in response to aging are similar to the changes that occur in other cells, and include increased oxidative stress, altered protein accumulation, nucleic acid damage, and dysfunction of energy homeostasis. ${ }^{59}$ The cellular changes during normal aging make neurons increasingly susceptible to excitotoxic damage ${ }^{59}$ through the impairment of ion pumps, ${ }^{60}$ dysregulation of $\mathrm{Ca}^{2+}$ homeostasis, ${ }^{59}$ and decreased mitochondrial function. ${ }^{61}$ Given that all these processes are involved in the evolution of the injury after traumatic insult, the process of aging itself could significantly increase vulnerability and impair the potential for recovery from TBI in aged individuals.

There is evidence that the brains of aged animals exhibit gene expression profiles characteristic of microglial activation and neuroinflammation. ${ }^{62-65}$ Microglia themselves also appear to respond to stimulation with an amplified inflammatory response in aged animals. ${ }^{66}$ This neuroinflammatory priming can significantly affect the development of neurological dysfunction. Under normal conditions these inflammatory changes are temporary, and the microglia return to a dormant state as soon as the immune challenge is resolved. Aging, however, creates a brain environment in which microglial sensitivity to immune activation is increased and microglial activation does not resolve, which can lead to the pathogenesis of neurological disease. ${ }^{66}$ This situation is likely to exacerbate secondary injury in older subjects after TBI, in that trauma can lead not only to a severe systemic immune response, ${ }^{67}$ but also to immune factor release from the damaged cells within the brain itself. ${ }^{68}$

Exaggerated neuroinflammation can also interfere with neuroplasticity during the recovery phase, and inflammatory cytokines such as TNF $\alpha$, IL- $1 \beta$, and IL- 6 appear to directly interfere with long-term potentiation, ${ }^{69-71}$ memory consolidation, ${ }^{72}$ neurite outgrowth, ${ }^{73}$ and hippocampal neurogenesis. ${ }^{74}$ These data suggest that continued presence of reactive microglia in the aged brain creates an environment permissive to a prolonged and amplified neuroinflammatory response that can lead to subsequent complications, especially after TBI. ${ }^{66}$

\section{Systemic effects of aging and immunosenescence}

In addition to alterations in the CNS, age-related changes in the immune system are also common and have been implicated in virtually all age-associated disease processes. ${ }^{53}$ Aging is associated with a general activation of the inflammatory response, which, because of the chronic antigenic stress on innate immunity experienced over a lifetime, becomes the basis for the onset of inflammatory diseases ${ }^{51}$ and an increasing inability to mount an appropriate immune response to antigenic stimulation. ${ }^{53}$ With aging there is also a decrease in the production of anti-inflammatory hormones, ${ }^{75}$ as well as a general tendency toward production of elevated amounts of proinflammatory cytokines by peripheral blood mononuclear cells. ${ }^{54}$

The fulminating inflammatory state associated with increasing age has been dubbed inflammaging. ${ }^{54}$ This condition is systemic but also has specific effects within the CNS. ${ }^{66}$ Given the importance of inflammatory cytokines such as $\mathrm{TNF} \alpha$, IL-1 $\beta$, and IL-6 in both behavioral modulation and the evolution of traumatic injury, it is likely that an increased neuroinflammatory cytokine response in the elderly patient can disrupt neuronal synaptic plasticity, establishing a CNS environment predisposed to long-lasting complications, as well as a reduced ability to recover from trauma. ${ }^{66}$ In fact, the aged brain appears to exist in a chronic state of inflammation that is associated with increased immune reactivity and contin- 
uous low-level production of central inflammatory cytokines. $^{68}$

\section{Endocrine effects of aging}

In addition to structural and immune decline, human aging is associated with decreased activity in a number of systemic hormones, including thyroid hormone, ${ }^{47}$ sex steroids, ${ }^{46,49,76}$ growth hormone, ${ }^{48}$ insulin-like growth factor type 1 (IGF-I), ${ }^{48}$ and 25-hydroxyvitamin $\mathrm{D}_{3}{ }^{77,50,78}$ Especially intriguing is the relationship between endocrine decline and the change in immunological function. Some research suggests that proinflammatory cytokines may downregulate the physiological responses to a variety of hormones, including insulin, growth hormone, IGF-I, thyroid hormone, and estrogens. ${ }^{79}$

TNF $\alpha$, IL-1, and IL-6 can specifically modulate the release of growth hormone, growth hormone releasing hormone, and somatostatin, ${ }^{80}$ and are known to reduce concentrations of IGF-I ${ }^{81}$ and increase the concentrations of glucocorticoids ${ }^{82}$ in the serum of human patients. Lower serum IGF-I and dehydroepiandrosterone sulfate levels were found in frail (compared with nonfrail) elderly individuals, ${ }^{56}$ and an inverse correlation between serum IL-6 and IGF-I was noted only in frail individuals. ${ }^{56}$ Elevated levels of inflammatory cytokines ${ }^{83-86}$ and the development of frailty in older adults ${ }^{87,88}$ have also been associated with vitamin $\mathrm{D}$ deficiency (D-deficiency).

These data can be taken to suggest that the immune system and its age-associated dysfunction may be intimately related to the functioning of the neuroendocrine system, and that this relationship may further contribute to the development of systemic insufficiency and vulnerability to injury.

\section{Aging and vitamin D deficiency}

Of all the endocrine and nutritional disruptions that affect the elderly population, D-deficiency has recently received considerable attention, partly because an estimated 1 billion people worldwide exhibit D-deficiency or insufficiency. ${ }^{89}$ In the northeastern United States, studies show a prevalence from $32 \%$ in healthy adults ${ }^{90}$ to approximately $50 \%$ for adolescents and preadolescents. ${ }^{91-93}$ The most dramatic statistics for D-deficiency, however, come from studies in the elderly population, which show that 40 to $100 \%$ of community-dwelling American and European older men and women are Ddeficient. Even higher averages are seen in the ill and institutionalized. ${ }^{94-102}$

Vitamin D-deficiency has been associated with many systemic disorders, including infectious, inflammatory, and autoimmune conditions, ${ }^{103-109}$ cardiovascular disease, ${ }^{110,111}$ hypertension and atherosclerosis, ${ }^{112}$ neuromuscular function, ${ }^{113}$ cancer, ${ }^{114}$ neurodegenerative diseases, ${ }^{115,116}$ and neuropsychological and functional outcomes in the elderly population. ${ }^{117}$ In fact, D-deficiency appears to be correlated with many if not most of the problems associated with advanced age, especially those with an inflammatory component. ${ }^{103,106}$ There is also evidence that the level of serum vitamin D is a key marker of frailty, ${ }^{83,88}$ and that it is associated with elevated levels of IL-6. ${ }^{118}$

It is worth noting here that vitamin $\mathrm{D}$ is in fact not a vitamin, but rather a secosteroid hormone with the same cholesterol backbone as other steroids (including $\mathrm{P}_{4}$ ) and with its own class of nuclear steroid receptors and signaling mechanisms. ${ }^{119,120}$ In its biologically active form, 1,25-dihydroxyvitamin $\mathrm{D}_{3}$ (vitamin $\mathrm{D}$ hormone, or $\mathrm{VDH}$ ) is a hormone with sites of action throughout the CNS; it can be considered a neuroactive steroid, because it is both synthesized and has actions in the nervous system. Vitamin D hormone is also a known and potent modulator of the cell cycle, immune function, and calcium homeostasis. As such, it may be in important compound not only as an endogenous hormone, but also as a treatment in its own right, especially in combination with $\mathrm{P}_{4}$.

\section{AGING, BRAIN INJURY, AND NEUROSTEROIDS}

\section{Progesterone in aged rats}

Given the promising results with progesterone in young adult animals, we sought to determine if it would work as well in aged animals. ${ }^{121}$ The working hypothesis in our aging studies was that $\mathrm{P}_{4}$ would be effective in treating TBI in aged rats. We measured levels of inflammatory proteins, cell death, edema, and behavior during the acute phase of injury (24-72 $\mathrm{h}$ after TBI) in aged rats (20 months old, approximately equivalent to 60 years in humans) to determine the potential of $\mathrm{P}_{4}$ in reducing mortality after TBI. Injured animals treated with $8 \mathrm{mg} / \mathrm{kg}$ and $16 \mathrm{mg} / \mathrm{kg} \mathrm{P}_{4}$ beginning within the first hour after surgery showed decreased expression of cyclooxygenase-2, IL-6, and nuclear factor $\kappa \mathrm{B}(\mathrm{NF} \kappa \mathrm{B})$ at all time points examined, indicating a reduction in the acute inflammatory process compared with the aged rats given vehicle. The $16 \mathrm{mg} / \mathrm{kg} \mathrm{P}_{4}$ group also showed reduced neuronal apoptosis at all time points, and decreased edema and improved locomotor outcomes. Although the lowest $\mathrm{P}_{4}$ dosage used in previous studies in younger animals $(8 \mathrm{mg} / \mathrm{kg})$ was effective in the aged animals, overall it was not as effective as $16 \mathrm{mg} / \mathrm{kg}$, suggesting potentially altered $\mathrm{P}_{4}$ kinetics and metabolism in the older animals.

We also observed an association between increased levels of P-glycoprotein and reduced edema, suggesting that $\mathrm{P}_{4}$ may reduce cerebral edema both through its antiinflammatory effects on cytokine levels and through direct effects on the integrity of the blood-brain barrier. $\mathrm{P}$-glycoprotein is regulated through the pregnane $\mathrm{X}$ re- 
ceptor (PXR) ${ }^{122,123}$ and plays a critical role in removing toxic products from the cell. Progesterone has been shown to exert neuroprotective effects through the PXR. ${ }^{124}$ This raises the intriguing possibility that some of the post-TBI benefits of $\mathrm{P}_{4}$ may be effected through this relatively novel signaling mechanism.

\section{Consequences of D-deficiency for TBI and $\mathbf{P}_{4}$ treatment}

Given the effectiveness of $\mathrm{P}_{4}$ in aged rats after TBI and the prevalence of D-deficiency in the elderly population, we asked whether D-deficiency would affect the outcome of a brain injury and whether it would interfere with the benefits of $\mathrm{P}_{4}$ treatment in aged rats. Based on the current literature, we hypothesized that D-deficiency would exacerbate inflammation and reduce or eliminate the benefits of $\mathrm{P}_{4}$ treatment after TBI in aged animals. Because early onset of inflammation is taken as a reliable prognostic indicator of mortality in human patients with significant trauma, we measured acute inflammatory proteins, cell death, DNA damage, and short-term behavior as indicators of inflammation and secondary damage in D-deficient aged animals after TBI.

In general, we observed increased inflammation in aged rats with D-deficiency, whether our subjects were uninjured, injured but untreated, or injured and treated with $\mathrm{P}_{4} \cdot{ }^{125}$ Our results confirmed previous studies $^{103,106,126}$ suggesting that D-deficiency establishes a higher baseline level of inflammation, in effect priming the system for an increased immune-inflammatory response after brain injury. This elevated acute-phase response correlated with increased cell death and DNA damage, indicating a more severe secondary injury process. Vitamin D deficiency also affected sickness behaviors, such as movement and grooming, which strongly correlated (by general linear models) with the expression of TNF $\alpha$ and IL-6.

Our data can be taken to indicate that short-term alterations in locomotor behavior could serve as a rough behavioral indicator of brain inflammation in the acute phase after injury. Our models also indicated that both TNF $\alpha$ and IL- 6 were significantly increased by D-deficiency and that both cytokines showed deficiency-treatment interaction effects. We take this to mean that the increased expression of these inflammatory cytokines may play an important role in the cascade of toxic mechanisms underlying the attenuation of $\mathrm{P}_{4}$ benefits in D-deficiency. Also notable is the fact that, although most of the variability in TNF $\alpha$ was accounted for by injury, the level of IL-6 was affected primarily by Ddeficiency. This fits with other independent data connecting IL-6 levels with D-deficiency, frailty, and inflammation $^{88,118,127,128}$ and suggests to us that IL-6 may be the key cytokine involved in the detrimental effects of D- deficiency. The elevation in IL-6 was most evident in our data comparing D-deficient and D-normal animals after TBI and $\mathrm{P}_{4}$ treatment. Most of the other cytokines were elevated in D-deficient animals twofold or threefold, but IL-6 was increased nearly fivefold by $72 \mathrm{~h}$ after injury.

\section{Management of VDH deficiency}

Given the data from human studies showing that the level of IL-6 is the most accurate prognostic indicator of survival in the acute phase after TBI, our findings could have significant implications in the clinical setting. We suggest that elderly people be screened for potential Ddeficiency and provided with supplementation therapy after TBI, because they could be more frail and thus more likely to die from their injuries. Powner et al. ${ }^{129}$ point out that, during rehabilitation from severe TBI, as many as $40 \%$ of patients suffer from endocrine dysfunctions associated with sickness behaviors such as chronic fatigue, decreased libido, amenorrhea, increased anxiety, memory failure, depression, and anorexia, among others. Although for some of these symptoms it is speculative that vitamin D could be a helpful treatment, the costs of vitamin $\mathrm{D}$ supplementation are minor and it is easy to give, and the implications for the treatment of a number of disease conditions could be important for clinical practice.

Although it seems reasonable that supplementation with vitamin $\mathrm{D}$ in a deficient state would be equivalent to ongoing vitamin D sufficiency (i.e., acute correction of deficiency should be equivalent to no deficiency), there is no a priori reason to make this assumption. At $24 \mathrm{~h}$ after injury, we observed no differences in inflammatory cytokines between VDH-treated deficient and D-normal animals. By $72 \mathrm{~h}$ after injury, while there was still no difference with TNF $\alpha$ and IL- $1 \beta$ was still lower than in D-normal animals, levels of IL-6, NF $\kappa \mathrm{B}$ p65, and cell death were all higher in VDH-treated deficient than in D-normal animals. These findings can be taken to suggest that, at least with reference to IL-6 levels, acutely correcting D-deficiency is not as good as maintaining D-normal status. In other words, prevention could be better than acute treatment.

Vitamin D deficiency as a public health issue has received much attention recently in the popular press, as well as in the medical literature. Now we can add another benefit to maintaining a normal vitamin $\mathrm{D}$ status: it is not just good for the arteries and protective against cancer, it can also be a primary intervention against TBI-in some ways, the equivalent of wearing a seatbelt. Although further research needs to be done on this issue, we suggest that the findings are likely to apply across the developmental spectrum and not just to the elderly population (where it might be exacerbated because of complications from other health-related factors). 


\section{COMBINING $\mathrm{P}_{4}$ WITH VDH IN TREATING TBI IN THE AGED POPULATION}

\section{Rationale for combinatorial therapy in treating TBI}

Combination therapy is somewhat new to the area of brain injury, but it is a well-established pharmacological approach to a number of other diseases, such as HIVAIDS or tuberculosis, although most drug development still focuses on individual drugs targeting one or at most a few specific mechanisms. Two issues are involved: drug combination and target promiscuity, or pleiotropy.

Rationales for combining drugs include targeting multiple divergent mechanisms and overcoming single-drug limitations such as receptor kinetics, pharmacology, and signaling pathways. ${ }^{130,131}$ This idea has recently gained ground in the treatment of TBI. ${ }^{5}$ Because both $\mathrm{P}_{4}$ and VDH are pleiotropic and multifunctional, it is difficult to predict specific mechanisms of interaction, but both could be used to target cell death after TBI, for example, as one of the many mechanisms by which a brain injury evolves. On the one hand, $\mathrm{P}_{4}$ would reduce cell death by preventing release of cytochrome $\mathrm{c}$ from the mitochondria, upregulating the antiapoptotic $\mathrm{Bcl}-2$ protein, and downregulating the proapoptotic Bax protein..$^{1,26,132} \mathrm{Vi}$ tamin D hormone, on the other hand, would prevent the reactivation of cell cycle machinery, ${ }^{133-135}$ which is a common step toward apoptosis in terminally differentiated neurons, ${ }^{136,137}$ and would upregulate nerve growth factor (NGF), providing a strong external prosurvival signal. ${ }^{138,139}$ The two compounds would thus act in synergy and provide benefits greater than either compound alone.

Combining $\mathrm{P}_{4}$ and VDH, pleiotropic drugs that work primarily through intracellular receptors and transcription factors likewise merits serious consideration, as meeting the criteria posited by Vink and $\mathrm{Nimmo}^{4}$ in their review of multifunctional drugs for head injury. We strongly agree that a combinatorial approach to treatment is not only reasonable but may be essential, given the complexity and heterogeneity of human TBI and the fact that, of the 130 preclinical monotherapy drugs that have shown promise in treating brain injury, all have failed when taken to clinical trial. ${ }^{5}$

\section{Effectiveness of $\mathbf{P}_{\mathbf{4}}-\mathrm{VDH}$ combination after TBI in aged rats}

We recently demonstrated effectiveness of a combination of $\mathrm{P}_{4}$ and $\mathrm{VDH}$ in both in vitro and in vivo models. Combining VDH and $\mathrm{P}_{4}$ was shown to be effective in vitro in increasing the survival of primary cortical neurons under glutamate challenge, with the combination showing more neuroprotection than either compound alone at best dose. ${ }^{140} \mathrm{We}$ applied the same treatment concept to D-deficient aged rats with TBI and showed that the only treatment that reduced proteins measured (TNF $\alpha$, IL-1 $\beta$, IL-6, NF $\kappa$ B p65, activated caspase-3, and $\mathrm{p} 53$ ) in all cases by $72 \mathrm{~h}$ after injury was the combination of $\mathrm{P}_{4}$ and $\mathrm{VDH}(5 \mathrm{mg} / \mathrm{kg}$ in a single dose) compared with vehicle or either compound given alone. The combination treatment was also the only one that dramatically improved behavioral parameters, which our statistical models again showed to be strongly correlated with systemic inflammation and levels of TNF $\alpha$ and IL-6. Should these results be translatable to humans, the clinical implications are obvious: a combination treatment of $\mathrm{P}_{4}$ and VDH given to elderly patients with TBI should improve survival over $\mathrm{P}_{4}$ given alone to the same population.

Briefly summarized, we conclude that 1 ) in aged rats with brain injury, $\mathrm{P}_{4}$ is effective in reducing acute inflammation, a key indicator of survival in human patients; 2) D-deficiency increases acute-phase inflammation and attenuates the benefits of $\mathrm{P}_{4}$ treatment in aged rats with TBI, suggesting that such a deficiency could increase mortality after brain injury in human patients; 3 ) a combination of $\mathrm{P}_{4}$ and $\mathrm{VDH}$ partially reverses the effects of D-deficiency and reduces post-TBI acute inflammation in aged rats, suggesting that, should these results translate to the clinic, a simple vitamin D injection combined with $\mathrm{P}_{4}$ could help save many human lives. Vink and Nimmo ${ }^{4}$ address this theme directly:

The brain is the most complex organ in the body, and significant gaps still exist in our understanding of normal brain function and how it is affected by acute injury. Unlike other organ systems, we cannot readily relate cellular function to the function of the organ as a whole .... Nonetheless, we do understand that acute brain injury is a heterogeneous type of injury, made up of immediate and delayed anatomic, molecular, biochemical and physiological events that are both complex and multi-faceted. So complex are these interactions that the concept of a single magic bullet is no longer accepted by the research community, and the focus has now turned to interventions that can modulate a number of independent injury factors simultaneously [p. 37].

\section{Potential mechanisms of action}

Although $\mathrm{P}_{4}$ acts through a number of mechanisms to reduce cell death and improve functional recovery after $\mathrm{TBI},{ }^{36,141}$ here we propose that a key process in its ability to reduce inflammation after injury is the ability to inhibit proinflammatory Th1 and also stimulate anti-inflammatory Th2 immune responses. Although the Th1/ Th2 paradigm is not unproblematic, ${ }^{142}$ it is useful in understanding the role of the adaptive immune system in inflammation. Our explanatory model is based on the fact that Th1/Th2 differentiation marks a decisive event very much like a phase transition in the development of extended inflammation after severe injury.

As suggested earlier, this reduction in systemic inflammation may be one of the key mechanisms by which $\mathrm{P}_{4}$ 
significantly increases survival after TBI in human patients. ${ }^{39,40}$ With age, the general response of the immune system moves toward a proinflammatory condition ${ }^{54,66}$ that is associated with frailty and the increased susceptibility of aged organisms to external insult. ${ }^{55,56,143}$ This fact of increased inflammation and decreased immune flexibility with age could explain why we needed a larger dose of $\mathrm{P}_{4}$ in older animals to obtain similar effects on acute-phase reactants. In other words, anti-inflammatory effects need to be maximized to overcome the underlying predisposition toward inflammatory hyper-reactivity.

Under conditions of D-deficiency, the proinflammatory Th1 bias is elevated to a point at which $\mathrm{P}_{4}$ alone cannot counteract the amplification of the inflammatory cascade after injury. One way to prevent overwhelming inflammation after injury, then, is to combine pleiotropic drugs such as $\mathrm{P}_{4}$ and $\mathrm{VDH}$. Although the various gene regulatory and signaling mechanisms will be different, they will presumably synergize at the systemic level to inhibit Th1 differentiation, reduce the acute phase, and potentially improve outcome and survival.

\section{CONCLUSION}

A general approach to conceptualizing aging views it as a loss of systemic integration and adaptability that leads to a reduced ability to resist environmental perturbation, eventually leading to death. ${ }^{144}$ This decline of complex functioning in aging and disease has been observed in various systems, from cardiac rhythms and gait to cerebral autoregulation and large-scale brain network integration. ${ }^{145-151}$ Because of its association with frailty and various other age-related diseases, D-deficiency appears to have a similar destabilizing effect. ${ }^{83,152}$ Progesterone and especially VDH can be viewed as system stabilizers, as is evident from their beneficial effects on processes that range from DNA stability and cell cycle control to systemic immune function and hormone production..$^{50,133,153}$ Because severe TBI is essentially a massive perturbation that leads to activation and likely extreme overactivation of defensive responses (as in the case of inflammation, which although beneficial in the short term can also be highly damaging when overactive or prolonged), the introduction of stabilizing factors may allow for a reduction of this early damage and an improved ability to recover.

Acknowledgments: Portions of the research done at Emory University and described in this review were supported by National Institutes of Health grants 5R01NS048451 and 5R01HD061971. The authors would like to thank Leslie McCann for editorial assistance.

Disclosure: D.G.S. is entitled to royalty from products of BHR Pharma (Herndon, VA) related to the research described in this presentation, and may receive research funding from BHR, which is developing products related to this research. In addition, the author serves as consultant to BHR and receives compensation for these services. The terms of this arrangement have been reviewed and approved by Emory University in accordance with its conflict of interest policies.

\section{REFERENCES}

1. Schumacher M, Guennoun R, Stein DG, De Nicola AF. Progesterone: therapeutic opportunities for neuroprotection and myelin repair. Pharmacol Ther 2007;116:77-107.

2. Thurman DJ, Alverson C, Dunn KA, Guerrero J, Sniezek JE. Traumatic brain injury in the United States: a public health perspective. J Head Trauma Rehabil 1999;14:602-615.

3. Povlishock JT, Katz DI. Update of neuropathology and neurological recovery after traumatic brain injury. J Head Trauma Rehabil 2005;20:76-94.

4. Vink R, Nimmo AJ. Multifunctional drugs for head injury. Neurotherapeutics 2009;6:28-42.

5. Margulies S, Hicks R; Combination Therapies for Traumatic Brain Injury Workshop Leaders. Combination therapies for traumatic brain injury: prospective considerations. J Neurotrauma 2009;26:925-939.

6. Narayan RK, Michel ME, Ansell B, et al. Clinical trials in head injury. J Neurotrauma 2002;19:503-557.

7. Zygun DA, Kortbeek JB, Fick GH, Laupland KB, Doig CJ. Non-neurologic organ dysfunction in severe traumatic brain injury. Crit Care Med 2005;33:654-660.

8. Harwood PJ, Giannoudis PV, van Griensven M, Krettek C, Pape HC. Alterations in the systemic inflammatory response after early total care and damage control procedures for femoral shaft fracture in severely injured patients. J Trauma 2005;58:446-452; discussion 452-444.

9. Pape HC, Tsukamoto T, Kobbe P, Tarkin I, Katsoulis S, Peitzman A. Assessment of the clinical course with inflammatory parameters. Injury 2007;38:1358-1364.

10. Keel M, Trentz O. Pathophysiology of polytrauma. Injury 2005; 36:691-709.

11. Zygun D. Non-neurological organ dysfunction in neurocritical care: impact on outcome and etiological considerations. Curr Opin Crit Care 2005;11:139-143.

12. Shohami E, Gati I, Beit-Yannai E, Trembovler V, Kohen R. Closed head injury in the rat induces whole body oxidative stress: overall reducing antioxidant profile. J Neurotrauma 1999;16:365376.

13. Moinard C, Gupta S, Besson V, et al. Evidence for impairment of hepatic energy homeostasis in head-injured rat. J Neurotrauma 2008;25:124-129.

14. Bochicchio GV, Napolitano LM, Joshi M, McCarter RJ Jr, Scalea TM. Systemic inflammatory response syndrome score at admission independently predicts infection in blunt trauma patients. J Trauma 2001;50:817-820.

15. Malone DL, Kuhls D, Napolitano LM, McCarter R, Scalea T. Back to basics: validation of the admission systemic inflammatory response syndrome score in predicting outcome in trauma. J Trauma 2001;51:458-463.

16. Napolitano LM, Ferrer T, McCarter RJ Jr, Scalea TM. Systemic inflammatory response syndrome score at admission independently predicts mortality and length of stay in trauma patients. J Trauma 2000;49:647-652; discussion 652-643.

17. Nast-Kolb D, Waydhas C, Gippner-Steppert C, et al. Indicators of the posttraumatic inflammatory response correlate with organ failure in patients with multiple injuries. J Trauma 1997;42:446454; discussion 454-445.

18. Nuytinck HK, Offermans XJ, Kubat K, Goris JA. Whole-body inflammation in trauma patients: an autopsy study. Arch Surg 1988;123:1519-1524.

19. Gabay C, Kushner I. Acute-phase proteins and other systemic responses to inflammation. N Engl J Med 1999;340:448-454.

20. Gebhard F, Pfetsch H, Steinbach G, Strecker W, Kinzl L, Brückner UB. Is interleukin 6 an early marker of injury severity following major trauma in humans? Arch Surg 2000;135:291-295. 
21. Vodovotz Y, Csete M, Bartels J, Chang S, An G. Translational systems biology of inflammation. PLoS Comput Biol 2008;4: 1-6; e1000014.

22. Frink M, Pape HC, van Griensven M, Krettek C, Chaudry IH, Hildebrand F. Influence of sex and age on MODS and cytokines after multiple injuries. Shock 2007;27:151-156.

23. Attella MJ, Nattinville A, Stein DG. Hormonal state affects recovery from frontal cortex lesions in adult female rats. Behav Neural Biol 1987;48:352-367.

24. Roof RL, Stein DG. Progesterone treatment attenuates brain edema following contusion injury in male and female rats. Restor Neurol Neurosci 1992;4:425-427.

25. Goss CW, Hoffman SW, Stein DG. Behavioral effects and anatomic correlates after brain injury: a progesterone dose-response study. Pharmacol Biochem Behav 2003;76:231-242.

26. Djebaili M, Guo Q, Pettus EH, Hoffman SW, Stein DG. The neurosteroids progesterone and allopregnanolone reduce cell death, gliosis, and functional deficits after traumatic brain injury in rats. J Neurotrauma 2005;22:106-118.

27. Pettus EH, Wright DW, Stein DG, Hoffman SW. Progesterone treatment inhibits the inflammatory agents that accompany traumatic brain injury. Brain Res 2005;1049:112-119.

28. Djebaili M, Hoffman SW, Stein DG. Allopregnanolone and progesterone decrease cell death and cognitive deficits after a contusion of the rat pre-frontal cortex. Neuroscience 2004;123:349359.

29. Stein DG. Progesterone exerts neuroprotective effects after brain injury. Brain Res Rev 2008;57:386-397.

30. Guo Q, Baronne L, Hoffman SW, Guennoun R, Stein DG. Progesterone's effects on aquaporin-4 expression after traumatic brain injury in male rats. J Neurotrauma 2004;21:1303 (abstract).

31. Shear DA, Galani R, Hoffman SW, Stein DG. Progesterone protects against necrotic damage and behavioral abnormalities caused by traumatic brain injury. Exp Neurol 2002;178:59-67.

32. McCullough LD, Hurn PD. Estrogen and ischemic neuroprotection: an integrated view. Trends Endocrinol Metab 2003;14:228235.

33. Stein DG. Brain damage, sex hormones and recovery: a new role for progesterone and estrogen? Trends Neurosci 2001;24:386391.

34. Stein DG, Hoffman SW. Concepts of CNS plasticity in the context of brain damage and repair. J Head Trauma Rehabil 2003; 18:317-341.

35. Stein DG, Hoffman SW. Estrogen and progesterone as neuroprotective agents in the treatment of acute brain injuries. Pediatr Rehabil 2003;6:13-22.

36. Schumacher M, Guennoun R, Ghoumari A, et al. Novel perspectives for progesterone in hormone replacement therapy, with special reference to the nervous system. Endocr Rev 2007;28:387439.

37. Guo Q, Sayeed I, Baronne LM, Hoffman SW, Guennoun R, Stein DG. Progesterone administration modulates AQP4 expression and edema after traumatic brain injury in male rats. Exp Neurol 2006; 198:469-478.

38. Sayeed I, Guo Q, Hoffman SW, Stein DG. Allopregnanolone, a progesterone metabolite, is more effective than progesterone in reducing cortical infarct volume after transient middle cerebral artery occlusion. Ann Emerg Med 2006;47:381-389.

39. Wright DW, Kellermann AL, Hertzberg VS, et al. ProTECT: a randomized clinical trial of progesterone for acute traumatic brain injury. Ann Emerg Med 2007;49:391-402.

40. Xiao G, Wei J, Yan W, Wang W, Lu Z. Improved outcomes from the administration of progesterone for patients with acute severe traumatic brain injury: a randomized controlled trial. Crit Care 2008; 12:R61.

41. Chen G, Shi JX, Qi M, Wang HX, Hang CH. Effects of progesterone on intestinal inflammatory response, mucosa structure alterations, and apoptosis following traumatic brain injury in male rats. J Surg Res 2008;147:92-98.

42. Adekoya N, Thurman DJ, White DD, Webb KW. Surveillance for traumatic brain injury deaths: United States, 1989-1998. MMWR Surveill Summ 2002;51:1-14.
43. Mosenthal AC, Lavery RF, Addis M, et al. Isolated traumatic brain injury: age is an independent predictor of mortality and early outcome. J Trauma 2002;52:907-911.

44. McArthur DL, Chute DJ, Villablanca JP. Moderate and severe traumatic brain injury: epidemiologic, imaging and neuropathologic perspectives. Brain Pathol 2004;14:185-194.

45. Gómez PA, Lobato RD, Boto GR, De la Lama A, González PJ, de la Cruz J. Age and outcome after severe head injury. Acta Neurochir (Wien) 2000;142:373-380; discussion 380-381.

46. Vermeulen A, Kaufman JM, Goemaere S, van Pottelberg I. Estradiol in elderly men. Aging Male 2002;5:98-102.

47. Vermeulen A, Kaufman JM. Ageing of the hypothalamo-pituitary-testicular axis in men. Horm Res 1995;43:25-28.

48. Lanfranco F, Gianotti L, Giordano R, Pellegrino M, Maccario M, Arvat E. Ageing, growth hormone and physical performance. J Endocrinol Invest 2003;26:861-872.

49. Araujo AB, O'Donnell AB, Brambilla DJ, et al. Prevalence and incidence of androgen deficiency in middle-aged and older men: estimates from the Massachusetts Male Aging Study. J Clin Endocrinol Metab 2004;89:5920-5926.

50. Rammos G, Tseke P, Ziakka S. Vitamin D, the renin-angiotensin system, and insulin resistance. Int Urol Nephrol 2008;40:419426.

51. Vasto S, Candore G, Balistreri CR, et al. Inflammatory networks in ageing, age-related diseases and longevity. Mech Ageing Dev 2007;128:83-91.

52. Gruver AL, Hudson LL, Sempowski GD. Immunosenescence of ageing. J Pathol 2007;211:144-156.

53. Bulati M, Pellicanò M, Vasto S, Colonna-Romano G. Understanding ageing: biomedical and bioengineering approaches, the immunologic view. Immun Ageing 2008;5:9.

54. Franceschi C, Capri M, Monti D, et al. Inflammaging and antiinflammaging: a systemic perspective on aging and longevity emerged from studies in humans. Mech Ageing Dev 2007;128: 92-105.

55. Walston J, Hadley EC, Ferrucci L, et al. Research agenda for frailty in older adults: toward a better understanding of physiology and etiology: summary from the American Geriatrics Society/National Institute on Aging Research Conference on Frailty in Older Adults. J Am Geriatr Soc 2006;54:991-1001.

56. Fried LP, Tangen CM, Walston J, et al. Frailty in older adults: evidence for a phenotype. J Gerontol A Biol Sci Med Sci 2001; 56:M146-M156.

57. Hof PR, Morrison JH. The aging brain: morphomolecular senescence of cortical circuits. Trends Neurosci 2004;27:607-613.

58. Dickstein DL, Kabaso D, Rocher AB, Luebke JI, Wearne SL, Hof PR. Changes in the structural complexity of the aged brain. Aging Cell 2007;6:275-284.

59. Mattson MP, Magnus T. Ageing and neuronal vulnerability. Nat Rev Neurosci 2006;7:278-294.

60. Mattson MP. Excitotoxic and excitoprotective mechanisms: abundant targets for the prevention and treatment of neurodegenerative disorders. Neuromolecular Med 2003;3:65-94.

61. Melov S. Modeling mitochondrial function in aging neurons. Trends Neurosci 2004;27:601-606.

62. Godbout JP, Chen J, Abraham J, et al. Exaggerated neuroinflammation and sickness behavior in aged mice following activation of the peripheral innate immune system. FASEB J 2005;19: $1329-1331$

63. Frank MG, Barrientos RM, Biedenkapp JC, Rudy JW, Watkins LR, Maier SF. mRNA up-regulation of MHC II and pivotal pro-inflammatory genes in normal brain aging. Neurobiol Aging 2006;27:717-722.

64. Perry VH, Matyszak MK, Fearn S. Altered antigen expression of microglia in the aged rodent CNS. Glia 1993;7:60-67.

65. Sheffield LG, Berman NE. Microglial expression of MHC class II increases in normal aging of nonhuman primates. Neurobiol Aging 1998;19:47-55.

66. Godbout JP, Johnson RW. Age and neuroinflammation: a lifetime of psychoneuroimmune consequences. Neurol Clin 2006;24:521538.

67. Lenz A, Franklin GA, Cheadle WG. Systemic inflammation after trauma. Injury 2007;38:1336-1345. 
68. Dilger RN, Johnson RW. Aging, microglial cell priming, and the discordant central inflammatory response to signals from the peripheral immune system. J Leukoc Biol 2008;84:932-939.

69. Griffin R, Nally R, Nolan Y, McCartney Y, Linden J, Lynch MA. The age-related attenuation in long-term potentiation is associated with microglial activation. J Neurochem 2006;99:12631272.

70. Li AJ, Katafuchi T, Oda S, Hori T, Oomura Y. Interleukin-6 inhibits long-term potentiation in rat hippocampal slices. Brain Res 1997;748:30-38.

71. Vereker E, O'Donnell E, Lynch MA. The inhibitory effect of interleukin- $1 \beta$ on long-term potentiation is coupled with increased activity of stress-activated protein kinases. J Neurosci 2000;20:6811-6819.

72. Barrientos RM, Higgins EA, Biedenkapp JC, et al. Peripheral infection and aging interact to impair hippocampal memory consolidation. Neurobiol Aging 2006;27:723-732.

73. Neumann H, Schweigreiter R, Yamashita T, Rosenkranz K, Wekerle H, Barde YA. Tumor necrosis factor inhibits neurite outgrowth and branching of hippocampal neurons by a rho-dependent mechanism. J Neurosci 2002;22:854-862.

74. Vallières L, Campbell IL, Gage FH, Sawchenko PE. Reduced hippocampal neurogenesis in adult transgenic mice with chronic astrocytic production of interleukin-6. J Neurosci 2002;22:486492.

75. Straub RH, Miller LE, Schölmerich J, Zietz B. Cytokines and hormones as possible links between endocrinosenescence and immunosenescence. J Neuroimmunol 2000;109:10-15.

76. Jiang M, Huhtaniemi I. Polymorphisms in androgen and estrogen receptor genes: effects on male aging. Exp Gerontol 2004;39: 1603-1611.

77. Elmadfa I, Meyer AL. Body composition, changing physiological functions and nutrient requirements of the elderly. Ann Nutr Metab 2008;52 Suppl 1:2-5.

78. Holick MF. Sunlight and vitamin D for bone health and prevention of autoimmune diseases, cancers, and cardiovascular disease. Am J Clin Nutr 2004;80(6 Suppl):1678S-1688S.

79. Ferrucci L, Ble A, Bandinelli S, Lauretani F, Suthers K, Guralnik JM. A flame burning within. Aging Clin Exp Res 2004;16:240243.

80. Talhouk RS, Saadé NE, Mouneimne G, Masaad CA, SafiehGarabedian B. Growth hormone releasing hormone reverses endotoxin-induced localized inflammatory hyperalgesia without reducing the upregulated cytokines, nerve growth factor and gelatinase activity. Prog Neuropsychopharmacol Biol Psychiatry 2004;28:625-631.

81. Priego T, Granado M, Ibáñez de Cáceres I, Martín AI, Villanúa MA, López-Calderón A. Endotoxin at low doses stimulates pituitary GH whereas it decreases IGF-I and IGF-binding protein-3 in rats. J Endocrinol 2003;179:107-117.

82. Beishuizen A, Thijs LG. Endotoxin and the hypothalamo-pituitary-adrenal (HPA) axis. J Endotoxin Res 2003;9:3-24.

83. Topinkova E. Aging, disability and frailty. Ann Nutr Metab 2008;52 Suppl 1:6-11.

84. Nagpal S, Na S, Rathnachalam R. Noncalcemic actions of vitamin D receptor ligands. Endocr Rev 2005;26:662-687.

85. Richards JB, Valdes AM, Gardner JP, et al. Higher serum vitamin D concentrations are associated with longer leukocyte telomere length in women. Am J Clin Nutr 2007;86:1420-1425.

86. Moore ME, Piazza A, McCartney Y, Lynch MA. Evidence that vitamin $\mathrm{D}_{3}$ reverses age-related inflammatory changes in the rat hippocampus. Biochem Soc Trans 2005;33:573-577.

87. Boxer RS, Dauser DA, Walsh SJ, Hager WD, Kenny AM. The association between vitamin $\mathrm{D}$ and inflammation with the 6-minute walk and frailty in patients with heart failure. J Am Geriatr Soc 2008;56:454-461.

88. Morley JE, Haren MT, Rolland Y, Kim MJ. Frailty. Med Clin North Am 2006;90:837-847

89. Holick MF. Vitamin D deficiency. N Engl J Med 2007;357:266281.

90. Tangpricha V, Pearce EN, Chen TC, Holick MF. Vitamin D insufficiency among free-living healthy young adults. Am J Med 2002;112:659-662.
91. Gordon CM, DePeter KC, Feldman HA, Grace E, Emans SJ. Prevalence of vitamin D deficiency among healthy adolescents. Arch Pediatr Adolesc Med 2004;158:531-537.

92. Nadziejko C, Fang K, Narciso S, et al. Effect of particulate and gaseous pollutants on spontaneous arrhythmias in aged rats. Inhal Toxicol 2004; $16: 373-380$.

93. Sullivan SS, Rosen CJ, Halteman WA, Chen TC, Holick MF. Adolescent girls in Maine are at risk for vitamin D insufficiency. J Am Diet Assoc 2005;105:971-974.

94. Chatfield SM, Brand C, Ebeling PR, Russell DM. Vitamin D deficiency in general medical inpatients in summer and winter. Intern Med J 2007;37:377-382.

95. Corino A, D'Amelio P, Gancia R, et al. Hypovitaminosis D in internal medicine inpatients. Calcif Tissue Int 2007;80:76-80.

96. Eyles D, Brown J, Mackay-Sim A, McGrath J, Feron F. Vitamin $\mathrm{D}_{3}$ and brain development. Neuroscience 2003;118:641-653.

97. Eyles DW, Smith S, Kinobe R, Hewison M, McGrath JJ. Distribution of the vitamin D receptor and $1 \alpha$-hydroxylase in human brain. J Chem Neuroanat 2005;29:21-30.

98. Hewison M, Zehnder D, Bland R, Stewart PM. $1 \alpha$-Hydroxylase and the action of vitamin D. J Mol Endocrinol 2000;25:141-148.

99. Holick MF. McCollum Award Lecture, 1994. Vitamin D: new horizons for the 21st century. Am J Clin Nutr 1994;60:619-630.

100. Larrosa M, Gratacòs J, Vaqueiro M, Prat M, Campos F, Roqué M. Prevalence of hypovitaminosis D in elderly institutionalized residents: influence of a substitutive treatment [In Spanish]. Med Clin (Barc) 2001;117:611-614.

101. McGrath JJ, Féron FP, Burne TH, Mackay-Sim A, Eyles DW. Vitamin $\mathrm{D}_{3}$ : implications for brain development. J Steroid Biochem Mol Biol 2004;89-90:557-560.

102. Townsend K, Evans KN, Campbell MJ, Colston KW, Adams JS, Hewison M. Biological actions of extra-renal 25-hydroxyvitamin D- $1 \alpha$-hydroxylase and implications for chemoprevention and treatment. J Steroid Biochem Mol Biol 2005;97:103-109.

103. Hayes CE, Nashold FE, Spach KM, Pedersen LB. The immunological functions of the vitamin D endocrine system. Cell $\mathrm{Mol}$ Biol (Noisy-le-grand) 2003;49:277-300.

104. DeLuca HF, Zierold C. Mechanisms and functions of vitamin D. Nutr Rev 1998;56:S4-S10; discussion S54-S75.

105. Griffin MD, Xing N, Kumar R. Vitamin D and its analogs as regulators of immune activation and antigen presentation. Annu Rev Nutr 2003;23:117-145.

106. Cantorna MT, Zhu Y, Froicu M, Wittke A. Vitamin D status, 1,25-dihydroxyvitamin $\mathrm{D}_{3}$, and the immune system. Am J Clin Nutr 2004;80:1717S-1720S.

107. Mahon BD, Wittke A, Weaver V, Cantorna MT. The targets of vitamin $\mathrm{D}$ depend on the differentiation and activation status of CD4 positive T cells. J Cell Biochem 2003;89:922-932.

108. Holick MF. Evolution and function of vitamin D. Recent Results Cancer Res 2003;164:3-28.

109. Holick MF. Vitamin D: a millenium perspective. J Cell Biochem 2003;88:296-307.

110. Melamed ML, Muntner P, Michos ED, et al. Serum 25-hydroxyvitamin D levels and the prevalence of peripheral arterial disease: results from NHANES 2001 to 2004. Arterioscler Thromb Vasc Biol 2008;28:1179-1185.

111. Martins D, Wolf M, Pan D, et al. Prevalence of cardiovascular risk factors and the serum levels of 25-hydroxyvitamin D in the United States: data from the Third National Health and Nutrition Examination Survey. Arch Intern Med 2007;167:1159-1165.

112. Onyszchuk G, He YY, Berman NE, Brooks WM. Detrimental effects of aging on outcome from traumatic brain injury: a behavioral, magnetic resonance imaging, and histological study in mice. J Neurotrauma 2008;25:153-171.

113. Pfeifer M, Begerow B, Minne HW. Vitamin D and muscle function. Osteoporos Int 2002;13:187-194.

114. Peterlik M, Cross HS. Vitamin D and calcium deficits predispose for multiple chronic diseases. Eur J Clin Invest 2005;35: 290-304.

115. Garcion E, Wion-Barbot N, Montero-Menei CN, Berger F, Wion D. New clues about vitamin D functions in the nervous system. Trends Endocrinol Metab 2002;13:100-105. 
116. Kalueff AV, Lou YR, Laaksi I, Tuohimaa P. Increased anxiety in mice lacking vitamin D receptor gene. Neuroreport 2004;15: 1271-1274.

117. Dawson-Hughes B. Serum 25-hydroxyvitamin D and functional outcomes in the elderly. Am J Clin Nutr 2008;88:537S-540S.

118. McCarty MF. Secondary hyperparathyroidism promotes the acute phase response: a rationale for supplemental vitamin D in prevention of vascular events in the elderly. Med Hypotheses 2005; 64:1022-1026.

119. Dusso AS, Brown AJ, Slatopolsky E. Vitamin D. Am J Physiol Renal Physiol 2005;289:F8-F28.

120. van Etten E, Mathieu C. Immunoregulation by 1,25-dihydroxyvitamin $\mathrm{D}_{3}$ : basic concepts. J Steroid Biochem Mol Biol 2005;97: 93-101.

121. Cutler SM, Cekic M, Miller DM, Wali B, VanLandingham JW, Stein DG. Progesterone improves acute recovery after traumatic brain injury in the aged rat. J Neurotrauma 2007;24:1475-1486.

122. Bauer B, Hartz AM, Fricker G, Miller DS. Pregnane X receptor up-regulation of P-glycoprotein expression and transport function at the blood-brain barrier. Mol Pharmacol 2004;66:413-419.

123. Miller DS, Bauer B, Hartz AM. Modulation of P-glycoprotein at the blood-brain barrier: opportunities to improve central nervous system pharmacotherapy. Pharmacol Rev 2008;60:196-209.

124. Langmade SJ, Gale SE, Frolov A, et al. Pregnane X receptor (PXR) activation: a mechanism for neuroprotection in a mouse model of Niemann-Pick C disease. Proc Natl Acad Sci U S A 2006;103:13807-13812.

125. Cekic M, Cutler SM, Vanlandingham JW, Stein DG. Vitamin D deficiency reduces the benefits of progesterone treatment after brain injury in aged rats. Neurobiol Aging 2009 May 29 [Epub ahead of print].

126. Lips P. Vitamin D physiology. Prog Biophys Mol Biol 2006;92: 4-8.

127. Miller RR, Hicks GE, Shardell MD, et al. Association of serum vitamin D levels with inflammatory response following hip fracture: the Baltimore Hip Studies. J Gerontol A Biol Sci Med Sci 2007;62:1402-1406.

128. Van den Berghe G, Van Roosbroeck D, Vanhove P, Wouters PJ, De Pourcq L, Bouillon R. Bone turnover in prolonged critical illness: effect of vitamin D. J Clin Endocrinol Metab 2003;88: 4623-4632.

129. Powner DJ, Boccalandro C, Alp MS, Vollmer DG. Endocrine failure after traumatic brain injury in adults. Neurocrit Care 2006; 5:61-70.

130. Faden AI. Neuroprotection and traumatic brain injury: the search continues. Arch Neurol 2001;58:1553-1555.

131. Gingrich MB, Traynelis SF. Serine proteases and brain damage: is there a link? Trends Neurosci 2000;23:399-407.

132. Brinton RD, Thompson RF, Foy MR, et al. Progesterone receptors: form and function in brain. Front Neuroendocrinol 2008;29: 313-339.

133. Chatterjee M. Vitamin D and genomic stability. Mutat Res 2001; 475:69-87.

134. Cozzolino M, Lu Y, Finch J, Slatopolsky E, Dusso AS. p21WAF1 and TGF- $\alpha$ mediate parathyroid growth arrest by vitamin D and high calcium. Kidney Int 2001;60:2109-2117.
135. Jensen SS, Madsen MW, Lukas J, Binderup L, Bartek J. Inhibitory effects of $1 \alpha, 25$-dihydroxyvitamin $\mathrm{D}_{3}$ on the $\mathrm{G}_{1}-\mathrm{S}$ phasecontrolling machinery. Mol Endocrinol 2001;15:1370-1380.

136. Cernak I, Stoica B, Byrnes KR, Di Giovanni S, Faden AI. Role of the cell cycle in the pathobiology of central nervous system trauma. Cell Cycle 2005;4:1286-1293.

137. Di Giovanni S, Movsesyan V, Ahmed F, et al. Cell cycle inhibition provides neuroprotection and reduces glial proliferation and scar formation after traumatic brain injury. Proc Natl Acad Sci U S A 2005;102:8333-8338.

138. Brown J, Bianco JI, McGrath JJ, Eyles DW. 1,25-dihydroxyvitamin $\mathrm{D}_{3}$ induces nerve growth factor, promotes neurite outgrowth and inhibits mitosis in embryonic rat hippocampal neurons. Neurosci Lett 2003;343:139-143.

139. Wion D, MacGrogan D, Neveu I, Jehan F, Houlgatte R, Brachet P. 1,25-Dihydroxyvitamin $\mathrm{D}_{3}$ is a potent inducer of nerve growth factor synthesis. J Neurosci Res 1991;28:110-114.

140. Atif F, Sayeed I, Ishrat T, Stein DG. Progesterone with vitamin D affords better neuroprotection against excitotoxicity in cultured cortical neurons than progesterone alone. Mol Med 2009;15:328336.

141. Stein DG, Wright DW, Kellermann AL. Does progesterone have neuroprotective properties? Ann Emerg Med 2008;51:164-172.

142. Kidd P. Th1/Th2 balance: the hypothesis, its limitations, and implications for health and disease. Altern Med Rev 2003;8:223-246.

143. Paganelli R, Di Iorio A, Cherubini A, et al. Frailty of older age: the role of the endocrine-immune interaction. Curr Pharm Des 2006;12:3147-3159.

144. Lipsitz LA. Physiological complexity, aging, and the path to frailty. Sci Aging Knowledge Environ 2004;2004:pe16.

145. Lipsitz LA, Goldberger AL. Loss of 'complexity' and aging: potential applications of fractals and chaos theory to senescence. JAMA 1992;267:1806-1809.

146. Goldberger AL, Peng CK, Lipsitz LA. What is physiologic complexity and how does it change with aging and disease? Neurobiol Aging 2002;23:23-26.

147. Schulte-Frohlinde V, Ashkenazy Y, Goldberger AL, et al. Complex patterns of abnormal heartbeats. Phys Rev E Stat Nonlin Soft Matter Phys 2002;66(3 Pt 1):031901.

148. Costa M, Goldberger AL. Multiscale entropy analysis of complex physiologic time series. Phys Rev Lett 2002;89(6):068102.

149. Hausdorff JM, Peng CK, Goldberger AL, Stoll AL. Gait unsteadiness and fall risk in two affective disorders: a preliminary study. BMC Psychiatry 2004;4:39.

150. Novak V, Yang AC, Lepicovsky L, Goldberger AL, Lipsitz LA, Peng CK. Multimodal pressure-flow method to assess dynamics of cerebral autoregulation in stroke and hypertension. Biomed Eng Online 2004;3:39.

151. Andrews-Hanna JR, Snyder AZ, Vincent JL, et al. Disruption of large-scale brain systems in advanced aging. Neuron 2007;56: 924-935.

152. Villoslada P, Steinman L, Baranzini SE. Systems biology and its application to the understanding of neurological diseases. Ann Neurol 2009;65:124-139.

153. Adorini L, Penna G. Control of autoimmune diseases by the vitamin D endocrine system. Nat Clin Pract Rheumatol 2008;4: 404-412. 